\title{
Effect of Fatigue on Functional Stability of the Knee: Particularities of Female Handball Players
}

\author{
Authors \\ Timothée Gillot ${ }^{1,2}$, Maxime L'Hermette ${ }^{1}$, Typhanie Garnier ${ }^{1}$, Claire Tourny-Chollet ${ }^{1}$
}

\section{Affiliations}

1 Universite de Rouen UFR STAPS, CETAPS, EA 3832, Mont-Saint-Aignan, France

2 Rouen University Hospital, School of Physiotherapy, Rouen, France

\section{Key words}

anterior cruciate ligament, joint instability, laxity, fatigue, isokinetic ratio

accepted 23.02.2019

\section{Bibliography}

DOI https://doi.org/10.1055/a-0866-9482

Published online: 16.5.2019

Int J Sports Med 2019; 40: 468-476

(c) Georg Thieme Verlag KG Stuttgart · New York ISSN 0172-4622

\section{Correspondence}

Mr. Timothée Gillot, PT, PhD

Universite de Rouen, CETAPS, EA 3832, UFR STAPS,

4 Boulevard Siegfried,

76821 Mont-Saint-Aignan,

France

Tel.: + 33/667/844 043, Fax: + 33/667/844 043

timothee.gillot@gmail.com

\begin{abstract}
The risk of anterior cruciate ligament injury in female handball players is high. Fatigue of active stabilizers and increases in joint laxity are often mentioned in the literature as causal factors. However, no studies have been carried out on this population. Our objective is to determine the effect of muscle fatigue on active and passive knee stability in female handball players. This prospective study assessed tibiofemoral joint laxity, as well as hamstring and quadriceps strength, before $\left(T_{\text {initial }}\right)$, during and 3 min after $\left(T_{\text {final }}\right)$ an isokinetic fatigue protocol ( 25 repetitions of knee flexion / extension at $180^{\circ} . \mathrm{s}^{-1}$ ). Laxity values (slope of the displacement-load curve and anterior tibial translation) were measured using a GNRB-Rotab ${ }^{\circledR}$ arthrometer; torque values were measured at specific joint angles and peak muscle torque using an isokinetic dynamometer. Nineteen women $(20.9 \pm 2.4$ years, $62.0 \pm 4.9 \mathrm{~kg}, 166 \pm 5 \mathrm{~cm})$ were included. Normalized peak torque decreased significantly between the first three and last three repetitions of the fatigue protocol $(p<0.0001, E S=3.2$ and 3.2). Slope of the displacement-load curve and anterior tibial translation, functional and conventional ratios did not change significantly between $\mathrm{T}_{\text {initial }}$ and $\mathrm{T}_{\text {final. }}$. Active and passive markers of knee stability were not altered by a fatigue protocol in female handball players, suggesting these players have a large capacity for recovery. These results suggest that muscle strengthening to prevent $A C L$ injury in female handball players may be inappropriate. Level of evidence: Level 2b, Prospective Cohort.
\end{abstract}

\section{Introduction}

In handball, the risk of ACL injury is high, with 2.29 injuries / 1000 match-hours in Norway $[42,43,55]$. Depending on the level of practice, the risk for women is 1.6-4.6 times greater than for men $[30,47,49]$. In order to determine appropriate preventative strategies, interactions between risk factors and injury mechanisms should be analyzed using a sport-specific approach [3]. The etiology of ACL lesions is multifactorial, including neuromuscular, biomechanical, anatomical and hormonal factors [25, 40, 55, 57]. Twothirds of $A C L$ injuries that occur in handball result from non-contact situations such as during accelerations, pivots and changes of direction, overflows and jumps [7, 30, 40, 44, 45, 49]. Furthermore, in soccer it has been well identified that this injury happens mostly in the final stages of the match $[16,58]$. As muscles contribute to joint stability, neuromuscular fatigue is often suggested as a risk factor of non-contact ACL injuries [1]. Neuromuscular fatigue appears to affect the performance of muscles and ligaments in women [5]. Fatigue of proximal or distal muscles modifies joint kinematics during reception, affecting the dynamic valgus of the knee $[29,49]$, and should lead to changes in reactive strength of leg muscles [60]. Muscle strength, and particularly muscle balance (quadriceps and hamstrings for the sagittal plane), are key factors that determine joint stability $[9,11,12]$. Their deficit has been described as part of the mechanisms related to $A C L$ injuries and fatigue $[13,32,50,51]$. A study of 34 semi-professional male soccer players who carried out a concentric isokinetic endurance test showed that fatigue had a major but different effect on both quadriceps and hamstring strength (reduction of 54 and $65 \%$ respectively after 50 repetitions). This unequal reduction in strength reduces agonist/antagonist ratios, altering knee stability [53]. Another study 
evaluated sex differences in reflex hamstring responses and knee joint laxity before and after a fatigue protocol ( 25 women and 25 men with no history of injury). Compared with the men, latency of the hamstring reflex was longer in women under fatigue, with a significant reduction in activity of the biceps femoris and the semi-tendinous muscles in the 20-40 ms interval. Loaded anterior tibial translation was found to be significantly greater in women [5].

The aims of this study were 1 ) to determine the effects of muscle fatigue on active and passive knee stability in female handball players and 2) to evaluate the relationship between measures of muscle strength and ligament laxity / joint stability.( $($ Table 1)

\section{Materials and Methods}

This prospective study was carried out in a functional rehabilitation unit over a 3-month period during a competitive season, as part of the medical-athletic follow-up of the players.

\section{Subjects and study design}

Nineteen women $(20.9 \pm 2.39$ years, $62.00 \pm 4.86 \mathrm{~kg}, 166.32 \pm$ $5.32 \mathrm{~cm}$ ) with no progressive neurological or systemic diseases that could influence the active or passive structures of the knee participated in this study. All were second league handball players.

The inclusion criteria were: aged over 18 years old, right leg dominant athlete, with at least 5 years' experience in competitive handball, and $7 \mathrm{~h} /$ week practice on average. Leg dominance is subjectively defined by asking the subject which leg they would prefer to use to kick a ball as far as possible, as described in previous publications [21, 22, 26, 36]. The exclusion criteria were: previous $A C L$ rupture, recent traumatic injury to the right lower limb (including wounds) that required abstinence from competition during the 6 months preceding inclusion [33]. Players with significant onset of pain ( $>20 \mathrm{~mm}$ on the VAS) at the end of the warm-up or instability found on Lachman's test or an isokinetic dynamometer test were excluded. Pain VAS has been assessed with a continuous scale that is comprised of a horizontal line, 10 centimeters $(100 \mathrm{~mm})$ in length, anchored by two verbal descriptors, one for each extreme symptom: "no pain" (score of zero) and "pain as bad as it could be" or "worst imaginable pain" (score of 100 [100 mm scale]), $20 \mathrm{~mm}$ level corresponding to the minimal clinically important difference (MCID) mostly described in the literature [28].

\section{Experimental procedure}

The procedure involved fatiguing the quadriceps and hamstring muscles of the right leg. Isokinetic and posterior-anterior tibial translation measurements were taken before $\left(T_{\text {initial }}\right)$ and after 3 min of rest at the end of the fatigue protocol $\left(T_{\text {final }}\right)$. The order of the measurements was inversed between $T_{\text {initial }}$ and $T_{\text {final }}$ in order to limit set-up time. ( $\nabla$ Fig. 1). All subjects began with a standardized 10 min warm-up on a static bicycle at $120 \mathrm{~W}$, at a comfortable speed that corresponded to $62 \mathrm{rpm}$ on average $[2,23]$.

\section{Evaluation of posterior-anterior tibial translation}

The intrinsic stability of the knee joint was measured on the right knee using a GNRB-Rotab ${ }^{\circledR}$ ( $>$ Fig. 2). Sagittal tibial displacement and rotation were measured with the knee in $20^{\circ}$ of flexion [14]. A strap ensured symmetrical pressure on the patella during the test, controlled by a pressure sensor. The posterior-anterior displacement sensor was placed on the anterior tibial tuberosity. The foot was strapped in an articulated boot on which the tibial rotation sensor was fixed. A cylinder exerted a thrust of adjustable intensity on the upper part of the calf so as to translate the tibia anteriority on the femur.

The GNRB-Rotab ${ }^{\circledR}$ has been shown to accurately diagnose laxity at the knee joint and has excellent inter and intra-observer reliability $[6,8,35,52,56]$. Three $200 \mathrm{~N}$ thrusts were exerted on the tibia. $200 \mathrm{~N}$ force load level of thrust has been shown to have greater sensitivity and specificity than higher force levels [34, 39].

- Table 1 Isokinetic values.

\begin{tabular}{|c|c|c|c|c|c|c|c|c|}
\hline \multicolumn{9}{|c|}{ Peak force (PF) and normalized peak torque (NPT) values at $T_{\text {initial }}$ and $T_{\text {final }}$} \\
\hline$n=19$ & Qcon60 & Hcon60 & Qcon240 & Hcon240 & Qecc30 & Hecc30 & & \\
\hline$P F, T_{\text {initial }}$ & $638 \pm 117$ & $317 \pm 60$ & $394 \pm 65$ & $231 \pm 45$ & $822 \pm 179$ & $417 \pm 80$ & & \\
\hline$P F, T_{\text {final }}$ & $624 \pm 78$ & $320 \pm 62$ & $379 \pm 60$ & $325 \pm 44$ & $877 \pm 187$ & $438 \pm 77$ & & \\
\hline NPT, $T_{\text {initial }}$ & $2.72 \pm 0.48$ & $1.36 \pm 0.29$ & $1.67 \pm 0.24$ & $0.99 \pm 0.22$ & $3.51 \pm 0.77$ & $1.78 \pm 0.36$ & & \\
\hline $\mathrm{NPT}, \mathrm{T}_{\text {final }}$ & $2.67 \pm 0.33$ & $1.36 \pm 0.25$ & $1.61 \pm 0.22$ & $1.00 \pm 0.18$ & $3.76 \pm 0.84$ & $1.87 \pm 0.36$ & & \\
\hline \multicolumn{9}{|c|}{ Mean peak force (PF) and mean normalized peak torque (NPT) values during the first three and last three repetitions of fatigue protocol } \\
\hline$n=19$ & Q, First & H, First & Q, last & H, Last & & & & \\
\hline PF & $371 \pm 57$ & $224 \pm 38$ & $269 \pm 45$ & $174 \pm 44$ & & & & \\
\hline NPT & $1.58 \pm 0.05$ & $0,96 \pm 0.04$ & $1.15 \pm 0.04$ & $0.74 \pm 0.03$ & & & & \\
\hline \multicolumn{9}{|c|}{ Calculated ratios at specific joint angle at $\mathrm{T}_{\text {initial }}$ and $\mathrm{T}_{\text {final }}$} \\
\hline$n=19$ & $\mathrm{~T}_{\text {initial }}$ & & & & $T_{\text {final }}$ & & & \\
\hline Knee flexion angle & $45^{\circ}$ & $30^{\circ}$ & $15^{\circ}$ & PT & $45^{\circ}$ & $30^{\circ}$ & $15^{\circ}$ & PT \\
\hline Conv $60 / 60$ & $0.67 \pm 0.17$ & $0.98 \pm 0.29$ & $1.65 \pm 0.61$ & $0.51 \pm 0.10$ & $0.86 \pm 0.58$ & $0.92 \pm 0.24$ & $1.48 \pm 0.75$ & $0.51 \pm 0.09$ \\
\hline Conv $240 / 240$ & $0.61 \pm 0.14$ & $0.79 \pm 0.16$ & $1.16 \pm 0.24$ & $0.60 \pm 0.11$ & $0.63 \pm 0.18$ & $0.96 \pm 0.31$ & $1.71 \pm 0.66$ & $0.63 \pm 0.12$ \\
\hline Func $30 / 240$ & $1.15 \pm 0.30$ & $1.57 \pm 0.47$ & $2.43 \pm 0.78$ & $1.07 \pm 0.21$ & $1.36 \pm 0.40$ & $1.75 \pm 0.51$ & $3.28 \pm 1.45$ & $1.18 \pm 0.25$ \\
\hline
\end{tabular}

Values are mean \pm SD; PF values in Newton, NPT values in Nm. $\mathrm{kg}^{-1}$; Q: quadriceps; H: hamstrings; 60, 240, 30 refers to velocity; con: concentric; ecc: eccentric; SD: standard deviation of the mean; Conv: H/Q conventional ratio; Func: H/Q functional ratio. 


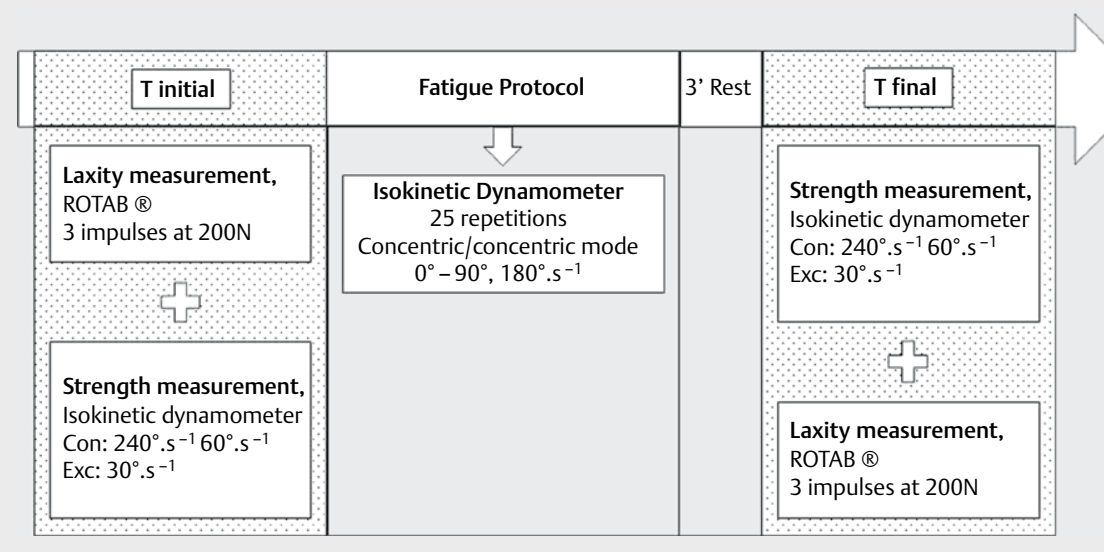

Fig. 1 Study Protocol.

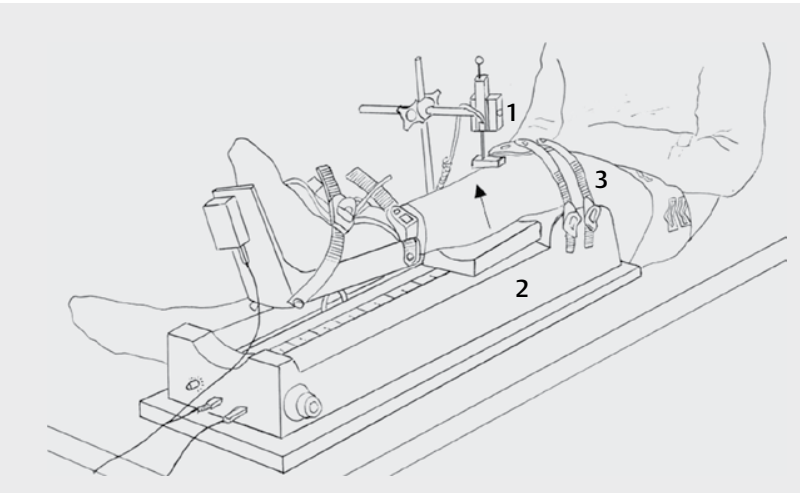

Fig. 2 Schematic drawing of the setup for measurement of posterior-anterior knee translation on the GNRB-Rotab ${ }^{\circledR}$. 1: posterioranterior tibial translation sensor, 2: actuator generating the posterior-anterior tibial translation, 3: patellar strap. Arrows indicate the direction of the force.

\section{Isokinetic evaluation}

Right knee flexor and extensor muscle strength were evaluated using a Kincom ${ }^{\circledR}$ isokinetic dynamometer (Kin-Com ${ }^{\circledR} 500 \mathrm{H}$ : Chattecx Corp., Chattanooga, TN, USA) with correction of the gravityinduced moment $[2,23]$, the subjects were seated with the hip flexed at $90^{\circ}$. The lever arm was placed two centimeters above the medial malleolus and its length recorded separately. Quadricep and hamstring strength values were recorded during consecutive flexion-extension movements over a range of $90^{\circ}$ of knee flexion to full extension in concentric mode and vice versa in eccentric mode, as indicated by the arrows in the $>$ Fig. $\mathbf{3}$. All subjects performed a warm-up of 10 submaximal concentric contractions at a velocity of $90^{\circ} . \mathrm{s}^{-1}$ for familiarization. Three tests were then performed by selecting "concentric" or "eccentric" mode in the controller of the isokinetic dynamometer: two concentric tests at $240^{\circ} . \mathrm{s}^{-1}$ and $60^{\circ} . \mathrm{s}^{-1}$ and an eccentric test at $30^{\circ} . \mathrm{s}^{-1}$. In concentric mode, quadriceps strength was recorded during the extension and hamstring strength during flexion, and vice versa in eccentric mode.
Three trials were carried out for each speed and strong verbal stimulation was given throughout: participants were asked to "push" or "pull" during concentric testing, and "resist" during eccentric testing. Three submaximal eccentric repetitions were performed at $90^{\circ} . \mathrm{s}^{-1}$ prior to the eccentric test at $30^{\circ} . \mathrm{s}^{-1}$ to familiarize the subjects with this highly demanding measurement mode. All subjects rested for $1 \mathrm{~min}$ between each series of tests [2].

\section{Fatigue protocol}

The fatigue protocol consisted of 25 maximal repetitions of concentric flexion / extension at $180^{\circ} . \mathrm{s}^{-1}$, performed on an isokinetic dynamometer according to a procedure that has been validated in soccer players $[4,53,54]$.

All subjects rested for $3 \mathrm{~min}$ at the end of the protocol, before $\mathrm{T}_{\text {final }}$ testing.

\section{Data analysis}

Dependent quantitative variables (peak muscle force, anterior tibial translation, slope of the displacement-load curve obtained on the GNRB-Rotab ${ }^{\circledR}$ ), length of the isokinetic dynamometer lever arm and body mass were recorded.

Peak extensor and flexor force $(\mathrm{N})$ were recorded for each test as well as during the first three and last three repetitions of the fatigue protocol. Hamstring $(\mathrm{H})$ and quadricep $(\mathrm{Q})$ force values at specific joint angles were logged for further analysis at $15^{\circ}, 30^{\circ}$ and $45^{\circ}$ of knee flexion for each test.

Quadriceps and hamstring peak forces, as well as forces at specific joint angles, were multiplied by the length $(\mathrm{m})$ of the isokinetic dynamometer lever arm and normalized by the body mass $(\mathrm{kg})$ of the athlete to obtain the normalized torques (normalized torque $=\frac{\text { force } * \text { lever arm }}{\text { body mass }}$ ) at each velocity $\left(240,60\right.$ and $\left.30^{\circ} \cdot \mathrm{s}^{-1}\right)$. H/Q conventional muscle ratios (concentric $\mathrm{H} /$ concentric Q) at 240 and $60^{\circ} \cdot \mathrm{s}^{-1}$ and $\mathrm{H} / \mathrm{Q}$ functional ratios (eccentric $\mathrm{H} 30^{\circ} \cdot \mathrm{s}^{-1} /$ concentric $\mathrm{Q} 240^{\circ} \cdot \mathrm{s}^{-1}$ ) were then calculated for each value of knee flexion (15, 30 and $45^{\circ}$ ) and at peak torques $[9,10]$. Specific joint angle $H / Q$ ratios measurement has been used in recent studies and allows a more functional overview of ratios at the injury ranges of motions $\left(0-30^{\circ}\right)$, where- 

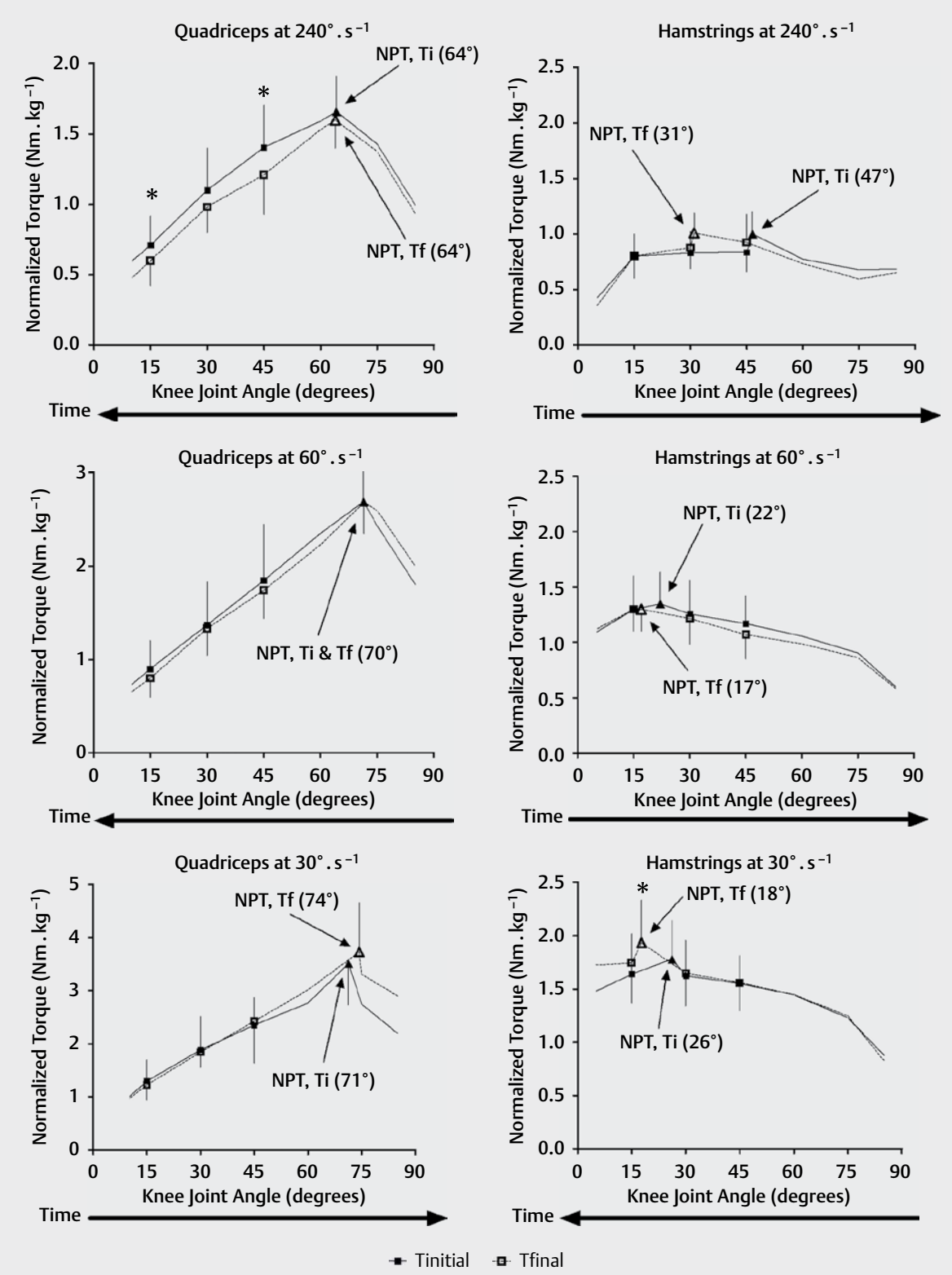

- Fig. 3 Quadriceps and hamstrings normalized torques at specific joint angles (square) and peak (triangles), at 30, 60 and $240^{\circ} . \mathrm{s}^{-1}$. Data are displayed as means \pm standard deviations. Values are highlited at $\mathrm{T}_{\text {initial }}$ (filled symbols) and $\mathrm{T}_{\text {Final }}$ (open symbols). NPT: normalized peak torque, Ti: $\mathrm{T}_{\text {initial }}, \mathrm{Tf}_{\mathrm{T}} \mathrm{T}_{\text {Final }}$. Arrows shows the direction of the angle sequence during recording. ${ }^{*}$ denotes a significant difference between $\mathrm{T}_{\text {initial }}$ and $\mathrm{T}_{\text {Final }}$, ${ }^{*} \mathrm{p}<0.05$.

as peak concentric and eccentric quadriceps torque production is likely to occur in the mid-late range of the movement $\left(40-80^{\circ}\right.$ of flexion) $[17,59]$.

GNRB-Rotab ${ }^{\circledR}$ values were recorded by the device software. The slope of the displacement-load curves (anterior tibial translation $\mathrm{mm}$ / force load in newtons), which reflects ligament elasticity, provided an overview of laxity [35]. Slope of the displacement-load curve $\left(\mathrm{mm} . \mathrm{N}^{-1}\right)$ and tibial translation $(\mathrm{mm})$ data were recorded for the right leg at $\mathrm{T}_{\text {Initial }}$ and $\mathrm{T}_{\text {Final }}$. Values for the second thrust were analyzed for each subject to avoid bias associated with any apprehension during the GNRB-Rotab ${ }^{\circledR}$ measurements $[34,39]$.

\section{Ethical approval}

The study was conducted according to the declaration of Helsinki and the ethical standards of the International Journal of Sports Medicine, and was approved by the University ethics committee [27]. Participation in the protocol lasted for around $2 \mathrm{~h}$ per subject. All subjects freely signed the informed consent prior to inclusion.

\section{Statistical analysis}

SPSS 20.0 (SPSS Inc., Chicago, IL, USA) was used for statistical analysis. Data were checked for normal distribution using the ShapiroWilk test and homogeneity using Levene's test. Quantitative, 
dependent variables measured at $\mathrm{T}_{\text {initial }}$ and $\mathrm{T}_{\text {final }}$ and during the fatigue protocol were homogenous and normally distributed, thus parametric tests were used. Differences between the values at $\mathrm{T}_{\text {initial }}$ and $\mathrm{T}_{\text {final }}$ were analyzed using a Student's-t test. Correlations between isokinetic dynamometer and laximetry variables were calculated with a Pearson's correlation coefficient, by using the difference of the final and initial values of each parameter as representative of the change due to the fatigue protocol $\left(\Delta_{X}=X_{\text {final }}-X_{\text {initial }}\right.$, where $X$ is any of the variables studied). The following scale was used to evaluate the level of correlation (in absolute values, the sign indicates the direction of the correlation): $r>0.81=$ very good correlation, $0.61<r<0.8=$ good correlation, $0.41<r<0.6=$ medium correlation, $r<0.41=$ poor correlation [31]. In each case the level of significance was established at $\alpha=0.05$. Effect sizes (ES) were calculated using the statistical software package $G$ * Power (Version 3.1.9.2) [19]. The ES characterizes the degree of effectiveness of an intervention. Effect sizes between 0.10 and 0.25 were considered small, between 0.25 and 0.40 medium and above 0.40 as large [18].

\section{Results}

Normalized peak concentric quadriceps torque did not change between $\mathrm{T}_{\text {initial }}$ and $\mathrm{T}_{\text {final }}$ at $60^{\circ} \cdot \mathrm{s}^{-1}(\mathrm{p}=0.521, \mathrm{ES}=0.15)$ or $240^{\circ} \cdot \mathrm{s}^{-1}$ $(p=0.278, E S=0.257)$. Normalized peak eccentric quadriceps torque did not change between $T_{\text {initial }}$ and $T_{\text {final }}(p=0,121$, ES $=$ $-0,374)$. Normalized peak concentric hamstring torque did not change between $\mathrm{T}_{\text {initial }}$ and $\mathrm{T}_{\text {final }}$ at $60^{\circ} \cdot \mathrm{s}^{-1}(\mathrm{p}=0.952, \mathrm{ES}=-0.140)$ or $240^{\circ} \cdot \mathrm{s}^{-1}(p=0.751$, ES $=-0.074)$. Normalized peak eccentric hamstring torque (at $30^{\circ} \cdot \mathrm{s}^{-1}$ ) increased significantly from $\mathrm{T}_{\text {initial }}$ to $\mathrm{T}_{\text {final }}(\mathrm{p}=0.05, \mathrm{ES}=-4.810)$ ( $>$ Fig. 3 ).

Normalized concentric quadriceps $240^{\circ} \cdot \mathrm{s}^{-1}$ torque decreased significantly from $T_{\text {initial }}$ to $T_{\text {final }}$ at $45^{\circ}(p=0.021, E S=0.582)$ and $15^{\circ}$ of knee flexion $(p=0.05, E S=0.481)$ ( $\triangleright$ Fig. 3 ).

There were no changes in peak functional ratios $(p=0.087$, $E S=0.416)$ or peak conventional ratios at $60^{\circ} \cdot \mathrm{s}^{-1}(p=0.915$, $E S=-0.025)$ and $240^{\circ} \cdot s^{-1}(p=0.205$, ES $=-0.302)$. Angle-specific $\mathrm{H} / \mathrm{Q}$ functional ratio increased significantly at $45^{\circ}(\mathrm{p}=0,049$, $E S=0.484)$ and $15^{\circ}(p=0,010$, ES $=0.664)$ of knee flexion. Anglespecific $\mathrm{H} / \mathrm{Q}$ conventional $240^{\circ} \cdot \mathrm{s}^{-1}$ ratio increased significantly at $30^{\circ}(p=0,008, E S=0.690)$ and $15^{\circ}$ of knee flexion $(p=0,001$, $E S=0.948$ and $>$ Fig. 4). Slope of the displacement-load curve obtained on the GNRB-Rotab ${ }^{\circledR}$ did not change between $T_{\text {initial }}$ and $T_{\text {final }}(p=0.246, E S=-0.25)$, neither did tibial translation $(p=0.473$, $E S=-0.168)$.

Normalized concentric peak torques during the first three and last three repetitions of the fatigue protocol decreased significant-
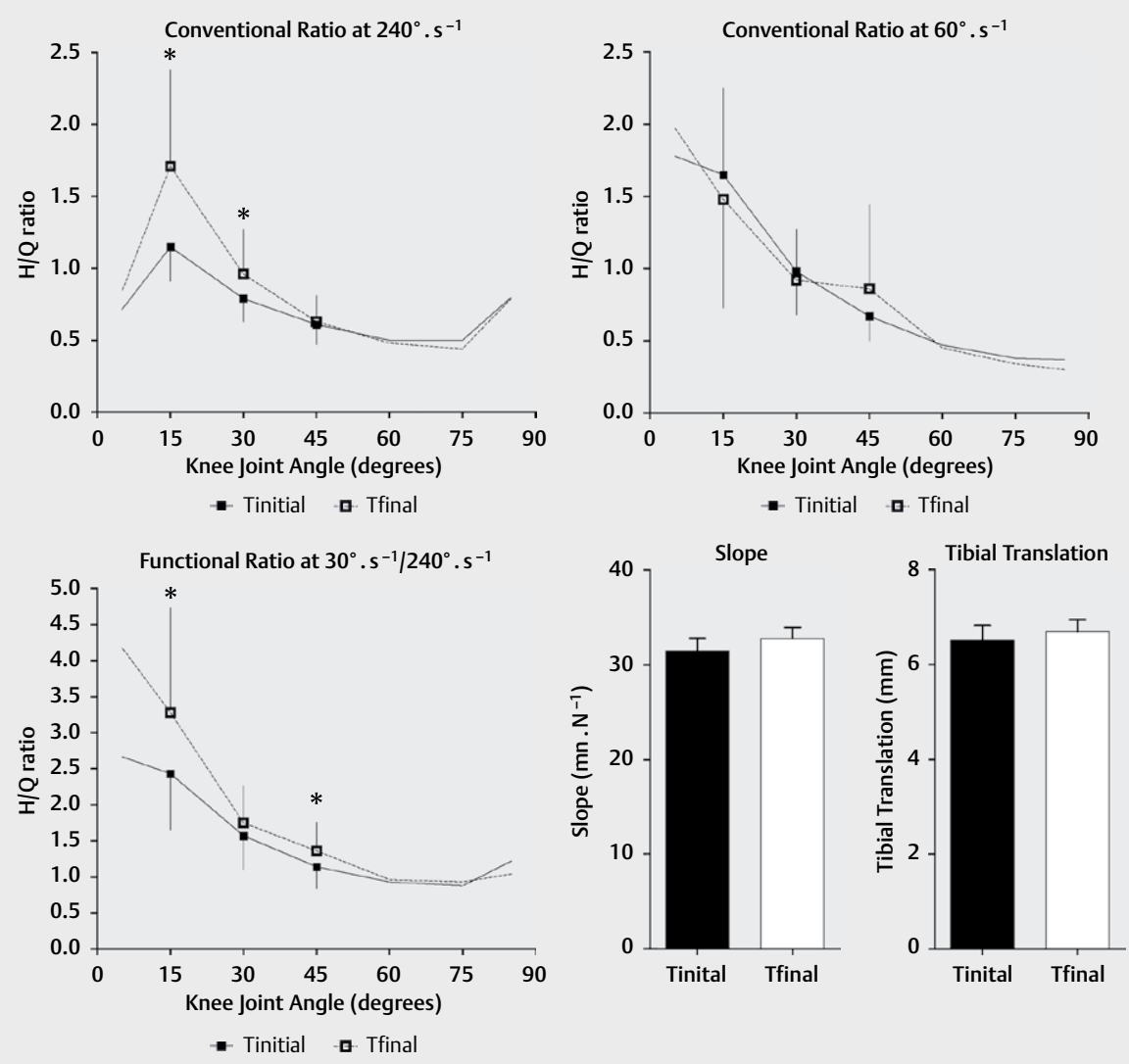

- Fig. 4 Effect of fatigue on laxity parameters and calculated isokinetic ratios at specific joint angles. Data are displayed as means \pm standard deviations. H/Q ratio are calculated with normalized torque values; $60,240,30$ refer to velocity. ${ }^{*}$ denotes a significant difference between $\mathrm{T}_{\text {initial }}$ and $\mathrm{T}_{\text {Final }}{ }^{*} \mathrm{p} \leq 0.05$. 

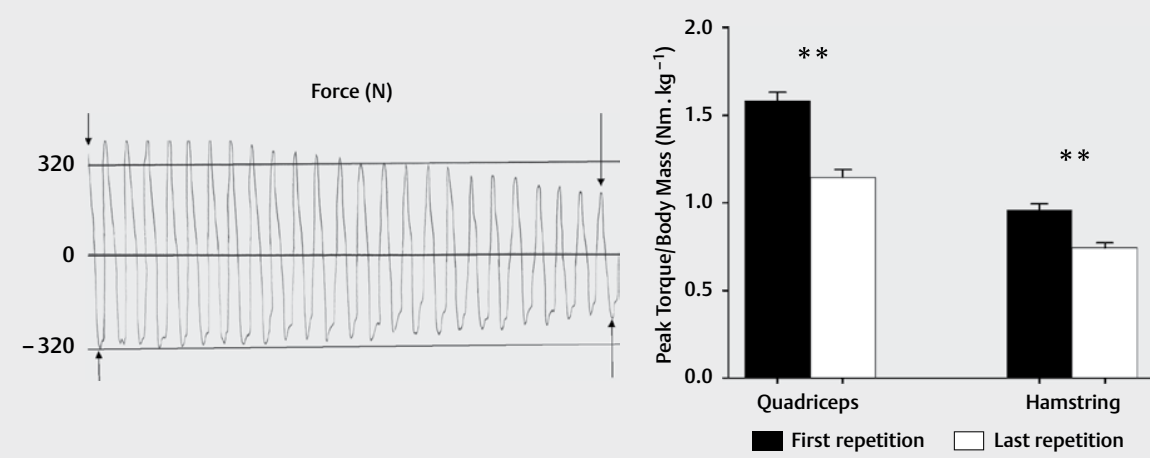

- Fig. 5 Strength curve from one representative subject during the fatigue protocol. Arrows indicate the measurement time for each value. Data are displayed in Newton $(\mathrm{N})$; Right: Histogram data are displayed as means \pm standard deviation of the mean. * denotes a significant difference between $\mathrm{T}_{\text {initial }}$ and $\mathrm{T}_{\text {Final }},{ }^{*} \mathrm{p}<0.05,{ }^{* *} \mathrm{p} \leq 0.001$.

ly in both the quadriceps $(p<0.0001, E S=2.496)$ and the hamstrings $(p<0.0001, E S=1.000)$ ( $\vee$ Fig. 5 ).

The variations of slope of the displacement-load curve and tibial translation values between $\mathrm{T}_{\text {initial }}$ and $\mathrm{T}_{\text {final }}$ were significantly correlated $(r=0.932, p<0.0001)$, however there was no correlation between isokinetic and GNRB-Rotab ${ }^{\circledR}$ values.

\section{Discussion}

The aim of this study was to determine the effects of muscle fatigue on knee stability. During the fatigue protocol test a significant reduction in normalized peak torque has been recorded. The large effect sizes showed that the 25 concentric repetitions at $180^{\circ} \cdot \mathrm{s}^{-1}$ effectively fatigued the quadriceps and hamstrings muscles $(p<0.0001$, ES $=2.496$ and 1.000, respectively). However, comparison of the results of the tests carried out before and $3 \mathrm{~min}$ after the fatigue protocol showed recovery of peak concentric and eccentric quadriceps torque and peak concentric hamstrings torque, but not peak eccentric hamstrings torque. Intrinsic knee stability did not decrease after the fatigue protocol.

\section{Analysis of descriptive parameters}

The results of this study seemed to show that pre-fatigue $\left(\mathrm{T}_{\text {initial }}\right)$ and post-fatigue $\left(T_{\text {final }}\right)$ average $H / Q$ conventional ratios at 60 and $240^{\circ} \cdot \mathrm{s}^{-1}$ were greater than the optimal ratios described by Croisier and Crielaard for agonist / antagonist muscle balance [10]. However, they were in the same order of magnitude as the measurements made by Lund-Hanssen et al. [37]. This latter study evaluated 114 elite Scandinavian handball players who played at a higher level than the present sample. The results of our study are close to the ratio measured in their population, with $0.51 \pm 0.10$ at $60^{\circ} \cdot \mathrm{s}^{-1}$ and $0.60 \pm 0.11$ at $240^{\circ} \cdot \mathrm{s}^{-1}$, respectively, in the present study versus 0.56 and 0.72 in the study by Lund-Hanssen et al. [37]. However, the values expressed at these speeds by these authors appear to be quite high and may be related to the measurement method, which is not sufficiently described. The high $\mathrm{H} / \mathrm{Q}$ ratio could be explained by relative weakness of the quadriceps; however, this is unlikely in elite players, and more likely indicates a high level of torque generated by the hamstrings, above that of the general population. Epidemiological data from a sample similar to that of Lund-Hanssen et al. shows that the risk of ACL injury remains high $[41,42]$. A longitudinal study is necessary in order to determine the risk of injury related to a low or high ratio at $240^{\circ} \cdot \mathrm{s}^{-1}$.

Studies that have used the GNRB-Rotab ${ }^{\circledR}$ to evaluate knee stability have used heterogenous levels of thrust, and thus it is difficult to compare data. However, the values recorded for postero-anterior tibial translation were comparable to those of another prospective study of 118 subjects that used a $200 \mathrm{~N}$ thrust $(0.70 \mathrm{~mm} \pm 0.50$ versus $0.65 \pm 0.15$ in this study) [34].

\section{Effect of the fatigue protocol on knee stability}

Differences in the values of peak muscle torque, anterior tibial translation, slope of the displacement-load curve obtained on the $\mathrm{GNRB}^{\circledR}$ between $\mathrm{T}_{\text {initial }}$ and $\mathrm{T}_{\text {final }}$ were not significant. Both the peak $\mathrm{H} / \mathrm{Q}$ conventional and peak $\mathrm{H} / \mathrm{Q}$ functional ratios remained stable between $T_{\text {initial }}$ and $T_{\text {final }}$. This could hypothetically reflect a homogeneous decrease in peak torques produced by the quadriceps and hamstrings. Thus, although the ratio is the same, the stability of the knee joint may be reduced. However, we observed a stability of the normalized peak torque for both hamstring and quadriceps during the fatigue protocol. There was only a significant increase in peak hamstring torque at $30^{\circ} \cdot \mathrm{s}^{-1}$ (eccentric) between $\mathrm{T}_{\text {initial }}$ and $\mathrm{T}_{\text {final }}(\mathrm{p}=0.05, E S=-4.81)$ that must be considered when interpreting the stability of the functional ratio. According to recent studies by De Ste Croix et al. and El-Ashker et al., a joint-angle-specific approach allows at this point a more functional and comprehensive overview [17, 59].

We observed a significant increase after fatigue of angle-specific $\mathrm{H} / \mathrm{Q}$ functional ratio at 45 and $15^{\circ}$ of knee flexion, explained by a decrease in the strength of the quadriceps at those angles while the strength of the hamstrings remains stable. In the same case, the significant increase of angle-specific $\mathrm{H} / \mathrm{Q}$ conventional $240^{\circ} \cdot \mathrm{s}^{-1}$ ratio at 30 and $15^{\circ}$ of knee flexion is mainly due to the significant decrease in the strength of the quadriceps at $15^{\circ}$ and the stability of hamstrings strength at $30^{\circ}$ of knee flexion ( $\vee$ Fig. 3,4 ). Therefore, active knee stability at the injury ranges of motions appears 
to increase after an isokinetic fatigue protocol. This suggests an adaptability of the muscular dynamic control throughout the knee range of motion to provide active stability in a fatigued state. However, in the fatigued state, previously published data suggests that muscle activation occurred later, thus resulting in delay in this protective muscle action: Behrens et al. found in an EMG study that fatigue had a significant effect on the contraction latency of the biceps femoris and semitendinosus muscles, with a significant decrease in activity in the $20-40$ ms interval in a sample of 25 women [5].

A recent study by El-Ashker et al. found a significant reduction in the angle-specific $\mathrm{H} / \mathrm{Q}$ functional ratio as the knee moves towards full knee extension, suggesting that dynamic control were less effective in extended knee position [17]. In contrast, we found increased $\mathrm{H} / \mathrm{Q}$ ratios as the knee moves towards knee extension ( $\triangleright$ Fig. 4). The difference may be attributed to the measurement position (seated versus supine position in the El-Ashker et al. study) or to the categories of people who took part in the study (recreational adults versus competitive handball players). As far as the authors know, few studies examined angle-specific $\mathrm{H} / \mathrm{Q}$ ratios among women. This should be considered for further analysis as it provides meaningful data.

In both cases, the agonist / antagonist balance of a handball player's knee in a fatigued state appears to differ from that of a soccer player's. A similar study in soccer players showed that the H/Q conventional ratio decreases in the fatigued state, with a large effect of fatigue on concentric work by the quadriceps and the hamstrings and thus a decrease in knee stability [53].

Passive stability evaluated on the GNRB-Rotab ${ }^{\circledR}$ also remained stable between $T_{\text {initial }}$ and $T_{\text {final }}$. This contrasts with the results of Behrens et al. who found a significant increase in tibial translation in women after a maximum fatigue protocol [5]. An increase in tibial translation increases the risk of injury due to the alteration in axial loading and the decrease in tibial rotation and translation [5]. The difference in results may be attributed to the fact that Behrens et al. used a loaded evaluation that is closer to real-world conditions but cannot be carried out using the GNRB-Rotab ${ }^{\circledR}$. Future studies should use loaded measurements to increase the validity of the results for sports.

The correlation between slope of the displacement-load curve and anterior tibial translation measured on the GNRB-Rotab ${ }^{\circledR}$ was excellent. This is not surprising since both laxity parameters are related to the intrinsic quality of the ligament.

The lack of correlation between the GNRB-Rotab ${ }^{\circledR}$ and the isokinetic data suggests these measures are complementary. Both are relevant and could be used for the clinical assessment of athletes. They allow an accurate assessment of the intrinsic (ligament) and extrinsic (muscle) stability of the knee. Similarly, Behrens et al. found a lack of correlation between muscle strength and ligament laxity using the loaded measurement [5].

\section{Effectiveness of the fatigue protocol on the trained handball player}

The fatigue protocol effectively fatigued the quadriceps and hamstring muscles as shown by the decrease in normalized peak torque between the first three and last three repetitions. However, concentric tests at $\mathrm{T}_{\text {final }}$ suggest that the rest period of 3 min between the end of the fatigue protocol and the beginning of the $T_{\text {final }}$ test was sufficient to allow recovery. Handball is an intermittent sport, alternating intense phases of play and recovery phases. Manchado et al. identified a highly developed basic endurance capacity of female handball players [38]. Continuous measurements of heartrate during match play shows an high maximum oxygen uptake in competitive athletes correlated with the level and the amount of training of women's [24]. In this study a high capacity for rapid, intrinsic recovery should be hypothesized to explain the results at $\mathrm{T}_{\text {final }}$ regarding the high level of the players and the number of years of practice $(9.5 \pm 3.4$ years $)$.

\section{Limits}

The increase in the eccentric performance of the hamstrings at $30^{\circ} \cdot \mathrm{s}^{-1}$ between $\mathrm{T}_{\text {initial }}$ and $\mathrm{T}_{\text {Final }}$ may explain the stability of the functional ratio. However, it may result from habituation to the eccentric test. This test is particularly demanding and unusual. The three concentric 'warm-up' repetitions carried out at $90^{\circ} \cdot \mathrm{s}^{-1}$ may not have conditioned the subjects to the eccentric test, resulting in a low normalized peak torque at $\mathrm{T}_{\text {initial }}$.

The lack of difference in performance between $T_{\text {initial }}$ and $T_{\text {Final }}$ suggests that the 25 concentric repetitions were insufficient to create lasting fatigue and may not represent the demands of a 45 min match. However, this protocol was used since it had been validated in soccer players [53]. It is possible that fatigue has different effects in different sporting populations, thus different protocols should be used.

\section{Implications}

The results of the present study suggest female handball players may not be vulnerable to muscle fatigue when performing an isokinetic fatigue protocol. Thus, endurance training may not be appropriate to prevent $A C L$ injury in female handball players. Currently, handball-specific $A C L$ injury prevention programs do not all focus on endurance training $[41,46,48]$. A meta-analysis of existing prevention programs showed these programs do reduce the risk of ACL injury but did not find a statistically significant association between training components and outcome among ACL injury studies [15]. Prevention programs must be simple, adapted and produce rapid solutions in order for coaches and athletes to comply [20]. Removing the endurance component could lighten programs and increase compliance. However, the role of muscle endurance in $A C L$ injury should be evaluated using measures that reproduce on-field conditions to confirm the present results.

\section{Conclusion}

The results of this study suggest female handball players have a large capacity for recovery following an isokinetic neuromuscular fatigue protocol. The lack of change in both active and passive stability markers calls for further studies to be carried out in conditions of play, to better define the impact of neuromuscular fatigue on the risk of $A C L$ injury. 


\section{FINDINGS}

Active markers of knee stability respond differently to neuromuscular fatigue in female handball players, than for other sporting populations. Unloaded passive stability of the knee is not modified by neuromuscular fatigue.

\section{IMPLICATIONS}

Muscle endurance training may not be an important component for the prevention of $\mathrm{ACL}$ injuries in female handball players.

\section{CAUTION}

Fatigue has different effects in different sporting populations, calling for further studies to be carried out in conditions of play.

\section{Conflict of Interest}

The authors declare no conflict of interest.

\section{References}

[1] Alentorn-Geli E, Myer GD, Silvers HJ, Samitier G, Romero D, LázaroHaro C, Cugat R. Prevention of non-contact anterior cruciate ligament injuries in soccer players. Part 1: Mechanisms of injury and underlying risk factors. Knee Surg Sports Traumatol Arthrosc 2009; 17: 705-729

[2] Bradic A, Bradic ], Pasalic E, Markovic G. Isokinetic leg strength profile of elite male basketball players. J Strength Cond Res 2009; 23: 1332-1337

[3] Bahr R, Krosshaug T. Understanding injury mechanisms: A key component of preventing injuries in sport. Br J Sports Med 2005; 39: 324-329

[4] Barber-Westin SD, Noyes FR. Effect of fatigue protocols on lower limb neuromuscular function and implications for anterior cruciate ligament injury prevention training. Am J Sports Med 2017; 45: 3388-3396

[5] Behrens M, Mau-Moeller A, Wassermann F, Bruhn S. Effect of fatigue on hamstring reflex responses and posterior-anterior tibial translation in men and women. PLoS One 2013; 8: e56988

[6] Beldame J, Mouchel S, Bertiaux S, Adam J-M, Mouilhade F, Roussignol X, Dujardin F. Anterior knee laxity measurement: Comparison of passive stress radiographs Telos $(\circledR)$ and “Lerat”, and GNRB $(\circledR)$ arthrometer. Orthop Traumatol Surg Res 2012; 98: 744-750

[7] Boden BP, Sheehan FT, Torg JS, Hewett TE. Noncontact anterior cruciate ligament injuries: Mechanisms and risk factors. J Am Acad Orthop Surg 2010; 18: 520-527

[8] Collette M, Courville J, Forton M, Gagnière B. Objective evaluation of anterior knee laxity; comparison of the KT-1000 and GNRB ${ }^{\circledR}$ arthrometers. Knee Surg Sports Traumatol Arthrosc 2012; 20: 2233-2238

[9] Croisier JL, Codine P. (ed) Exercice Musculaire Excentrique. Issy-lesMoulineaux: Elsevier Masson; 2009; 191:

[10] Croisier JL, Crielaard JM. Exploration isocinétique: Analyse des paramètres chiffrés. Ann Phys Rehabil Med 1999; 42: 538-545
[11] Croisier JL, Crielaard JM. Méthodes d'exploration de la force musculaire: Une analyse critique. Ann Phys Rehabil Med 1999; 42: 311-322

[12] Croisier JL, Crielaard JM. Exploration isocinétique: Analyse des paramètres chiffrés. Ann Phys Rehabil Med 1999; 42: 538-545

[13] Dai B, Mao D, Garrett WE, Yu B. Anterior cruciate ligament injuries in soccer: Loading mechanisms, risk factors, and prevention programs. J Sport Health Sci 2014; 3: 299-306

[14] Décary S, Ouellet P, Vendittoli P-A, Desmeules F. Reliability of physical examination tests for the diagnosis of knee disorders: Evidence from a systematic review. Man Ther 2016; 26: 172-182

[15] Donnell-Fink LA, Klara K, Collins JE, Yang HY, Goczalk MG, Katz JN, Losina E. Effectiveness of knee injury and anterior cruciate ligament tear prevention programs: A meta-analysis. PLoS One 2015; 10 : e0144063

[16] Ekstrand ], Hägglund M, Waldén M. Injury incidence and injury patterns in professional football: The UEFA injury study. $\mathrm{Br}$ J Sports Med 2011; 45: 553-558

[17] El-Ashker S, Carson BP, Ayala F, De Ste Croix M. Sex-related differences in joint-angle-specific functional hamstring-to-quadriceps strength ratios. Knee Surg Sports Traumatol Arthrosc 2017; 25: 949-957

[18] Faul F, Erdfelder E, Buchner A, Lang A-G. Statistical power analyses using $G$ * Power 3.1: Tests for correlation and regression analyses. Behav Res Methods 2009; 41: 1149-1160

[19] Faul F, Erdfelder E, Lang A-G, Buchner A. G * Power: A flexible statistical power analysis program for the social, behavioral, and biomedical sciences. Behav Res Methods 2007; 39: 175-191

[20] Finch C. A new framework for research leading to sports injury prevention. J Sci Med Sport 2006; 9: 3-9 discussion 10

[21] Ford KR, Myer GD, Hewett TE. Valgus knee motion during landing in high school female and male basketball players. Med Sci Sports Exerc 2003; 35: 1745-1750

[22] Ford KR, Schmitt LC, Hewett TE, Paterno MV. Identification of preferred landing leg in athletes previously injured and uninjured: A brief report. Clin Biomech 2016; 31: 113-116

[23] González-Ravé JM, Juárez D, Rubio-Arias JA, Clemente-Suarez V], Martinez-Valencia MA, Abian-Vicen J. Isokinetic leg strength and power in elite handball players. J Hum Kinet 2014; 41: 227-233

[24] Granados C, Izquierdo M, Ibanez ], Bonnabau H, Gorostiaga E. Differences in physical fitness and throwing velocity among elite and amateur women's handball players. Int J Sport Med 2007; 860-867

[25] Hägglund M, Waldén M, Ekstrand J. Previous injury as a risk factor for injury in elite football: A prospective study over two consecutive seasons. Br ] Sports Med 2006; 40: 767-772

[26] Harrison EL, Duenkel N, Dunlop R, Russell G. Evaluation of single-leg standing following anterior cruciate ligament surgery and rehabilitation. Phys Ther 1994; 74: 245-252

[27] Harriss D, Macsween A, Atkinson G. Standards for ethics in sport and exercise science research: 2018 Update. Int J Sport Med 2017; 38: 1126-1131

[28] Hawker GA, Mian S, Kendzerska T, French M. Measures of adult pain: Visual Analog Scale for Pain (VAS Pain), Numeric Rating Scale for Pain (NRS Pain), McGill Pain Questionnaire (MPQ), Short-Form McGill Pain Questionnaire (SF-MPQ), Chronic Pain Grade Scale (CPGS), Short Form-36 Bodily Pain Scale (SF). Arthritis Care Res (Hoboken) 2011; 63: S240-S252

[29] Hewett TE, Myer GD, Ford KR, Heidt RS, Colosimo A], McLean SG, Van Den Bogert AJ, Paterno MV, Succop P. Biomechanical measures of neuromuscular control and valgus loading of the knee predict anterior cruciate ligament injury risk in female athletes: a prospective study. Am J Sports Med 2005; 33: 492-501

[30] American Orthopaedic Society for Sports Medicine. (ed) Understanding and Preventing Noncontact ACL Injuries. Human Kinetics 2007 
[31] Hopkins WG, Marshall SW, Batterham AM, Hanin J. Progressive statistics for studies in sports medicine and exercise science. Med Sci Sports Exerc 2009; 41: 3-12

[32] Hughes G, Watkins ]. A risk-factor model for anterior cruciate ligament injury. Sports Med 2006; 36: 411-428

[33] Institut national de la santé et de la recherche médicale (Inserm). (ed) Activité Physique: Contextes et Effets sur la Santé. Synthèse et Recommandations. Les éditions Inserm; 2008

[34] Klouche S, Lefevre N, Cascua S, Herman S, Gerometta A, Bohu Y. Diagnostic value of the GNRB ${ }^{\circledR}$ in relation to pressure load for complete ACL tears: A prospective case-control study of 118 subjects. Orthop Traumatol Surg Res 2015; 101: 297-300

[35] Lefevre N, Bohu Y, Naouri JF, Klouche S, Herman S. Validity of GNRB ${ }^{\circledR}$ arthrometer compared to Telos ${ }^{\mathrm{TM}}$ in the assessment of partial anterior cruciate ligament tears. Knee surgery, Sport Traumatol Arthrosc 2014; 22: $285-290$

[36] Lephart SM, Ferris CM, Riemann BL, Myers JB, Fu FH. Gender differences in strength and lower extremity kinematics during landing. Clin Orthop Relat Res 2002; 401: 162-169

[37] Lund-Hanssen H, Gannon J, Engebretsen L, Holen K, Hammer S. Isokinetic muscle performance in healthy female handball players and players with a unilateral anterior cruciate ligament reconstruction. Scand J Med Sci Sports 1996; 6: 172-175

[38] Manchado C, Tortosa-Martínez J, Vila H, Ferragut C, Platen P. Performance factors in women's team handball: Physical and physiological aspects-a review. J strength Cond Res 2013; 27: 1708-1719

[39] Mouton C, Theisen D, Meyer T, Agostinis H, Nührenbörger C, Pape D, Seil R. Combined anterior and rotational knee laxity measurements improve the diagnosis of anterior cruciate ligament injuries. Knee surgery, Sport Traumatol Arthrosc 2015; 23: 2859-2867

[40] Myklebust G. ACL prevention in female handball. Aspetar Sports Medicine Journal 2014; 3: 206-210

[41] Myklebust G, Engebretsen L, Braekken IH, Skjølberg A, Olsen OE, Bahr R. Prevention of anterior cruciate ligament injuries in female team handball players: A prospective intervention study over three seasons. Clin J Sport Med 2003; 13: 71-78

[42] Myklebust G, Maehlum S, Holm I, Bahr R. A prospective cohort study of anterior cruciate ligament injuries in elite Norwegian team handball. Scand J Med Sci Sports 1998; 8: 149-153

[43] Myklebust G, Steffen K. Prevention of ACL injuries: How, when and who? Knee surgery, Sport Traumatol Arthrosc 2009; 17: 857-858

[44] Noyes F, Barber-Westin S. Neuromuscular retraining in female adolescent athletes: Effect on athletic performance indices and noncontact anterior cruciate ligament injury rates. Sports 2015; 3 : $56-76$

[45] Noyes FR, Barber-Westin SD. Neuromuscular retraining intervention programs: Do they reduce noncontact anterior cruciate ligament injury rates in adolescent female athletes? Arthroscopy 2014; 30: 245-255
[46] Olsen OE, Myklebust G, Engebretsen L, Holme I, Bahr R. Exercises to prevent lower limb injuries in youth sports: Cluster randomised controlled trial. BMJ 2005; 330: 449

[47] Olsen OE, Myklebust G, Engebretsen L, Holme I, Bahr R. Relationship between floor type and risk of $\mathrm{ACL}$ injury in team handball. Scand J Med Sci Sports 2003; 13: 299-304

[48] Petersen W, Braun C, Bock W, Schmidt K, Weimann A, Drescher W, Eiling E, Stange R, Fuchs T, Hedderich J, Zantop T. A controlled prospective case control study of a prevention training program in female team handball players: The German experience. Arch Orthop Trauma Surg 2005; 125: 614-621

[49] Peterson JR, Krabak B]. Anterior cruciate ligament injury: Mechanisms of injury and strategies for injury prevention. Phys Med Rehabil Clin N Am 2014; 25: 813-828

[50] Pinto MD, Blazevich A], Andersen LL, Mil-Homens P, Pinto RS. Hamstring-to-quadriceps fatigue ratio offers new and different muscle function information than the conventional non-fatigued ratio. Scand J Med Sci Sports 2017; 28: 282-293

[51] Proske U, Morgan D, Brockett C, Percival P. Identifying athletes at risk of hamstring strains and how to protect them. Clin Exp Pharmacol Physiol 2004; 31: 546-550

[52] Robert H, Nouveau S, Gageot S, Gagnière B. Nouveau système de mesure des laxités sagittales du genou, le GNRB ${ }^{\circledR}$. Application aux ruptures complètes et incomplètes du ligament croisé antérieur. Revue de Chirurgie Orthopédique et Traumatologie 2009; 95: 207-213

[53] Sangnier S, Tourny-Chollet C. Comparison of the decrease in strength between hamstrings and quadriceps during isokinetic fatigue testing in semiprofessional soccer players. Int J Sports Med 2007; 28: 952-957

[54] Sangnier S, Tourny-Chollet C. Study of the fatigue curve in quadriceps and hamstrings of soccer players during isokinetic endurance testing. J Strength Cond Res 2008; 22: 1458-1467

[55] Scuderi GR, McCann P. (ed) Sports Medicine : A Comprehensive Approach. $2^{\text {nd }}$ edition Philadelphia: Mosby; 2004

[56] Senioris A, Rousseau T, L’Hermette M, Gouzy S, Duparc F, Dujardin F. Validity of rotational laxity coupled with anterior translation of the knee: A cadaveric study comparing radiostereometry and the Rotab ${ }^{\circledR}$. Knee 2017; 24: 289-294

[57] Shultz S], Schmitz RJ, Benjaminse A, Chaudhari AM, Collins M, Padua DA. ACL Research Retreat VI: An Update on ACL Injury Risk and Prevention. J Athl Train 2012; 47: 591-603

[58] Small K, McNaughton L, Greig M, Lovell R. The effects of multidirectional soccer-specific fatigue on markers of hamstring injury risk. J Sci Med Sport 2010; 13: 120-125

[59] De Ste Croix M, ElNagar YO, Iga J, Ayala F, James D. The impact of joint angle and movement velocity on sex differences in the functional hamstring/quadriceps ratio. Knee 2017; 24: 745-750

[60] Toumi H, Poumarat G, Best TM, Martin A, Fairclough ], Benjamin M. Fatigue and muscle-tendon stiffness after stretch-shortening cycle and isometric exercise. Appl Physiol Nutr Metab 2006; 31: 565-572 